\title{
CORRIGENDA
}

\section{Chronic stimulation of corticotropin-releasing factor receptor 1 enhances the anxiogenic response of the cholecystokinin system}

\author{
T Sherrin, C Todorovic, T Zeyda, CH Tan, PTH Wong, Y-Z Zhu and J Spiess
}

Molecular Psychiatry (2009) 14, 1143; doi:10.1038/mp.2008.9

Correction to: Molecular Psychiatry (2009) 14, 291-307; doi:10.1038/sj.mp.4002121
Following the publication of the above article, the authors noted that Dr Wong's name was spelt incorrectly. The complete and correct name of the author appears above.

\section{Identifying blood biomarkers for mood disorders using convergent functional genomics}

H Le-Niculescu, SM Kurian, N Yehyawi, C Dike, SD Patel, HJ Edenberg, MT Tsuang, DR Salomon, $\mathrm{JI}$ Nurnberger Jr and AB Niculescu

Molecular Psychiatry (2009) 14, 1143; doi:10.1038/mp.2008.73

Correction to: Molecular Psychiatry (2009) 14, 156-174; doi: $10.1038 / \mathrm{mp} .2008 .11$

Following the publication of the above article, the authors noted a lack of correct alignment of a heatmap and a numbers column during apposition to generate Figure 3a. The corrected figure is shown below. The data reported for sensitivity and specificity in Table 4 and elsewhere in the paper are correct.

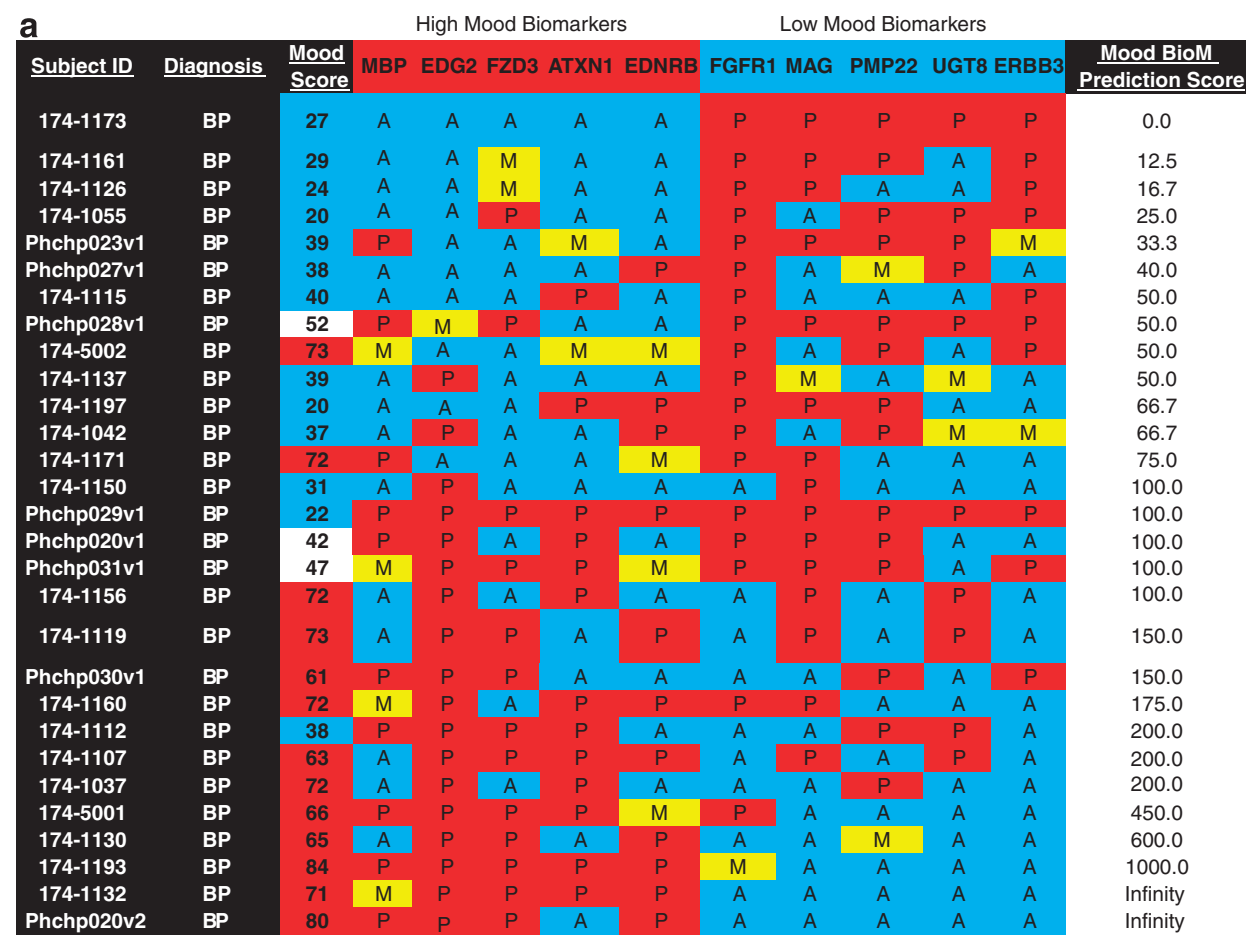

Figure 3 Top blood candidate biomarker genes for mood state. The lines of evidence scoring is depicted on the right side of the pyramid. 